\title{
GOUDRIAANS ANALYTISCHE ECONOMIE
}

\author{
door PROF. DR. J. TINBERGEN
}

1. Professor Goudriaan heeft in Zuid-Afrika de tijd gevonden een zijner uitspraken van vóór de oorlog uitvoerig toe te lichten, n.l. dat ,al wat er aan werkelijke exacte wetenschappelijke waarheid op economisch gebied bestaat..... zich (laat) samenvatten in een dun boekje van misschien twaalf of zestien bladzijden". ${ }^{1}$ ) De toelichting is, zoals men weet, wat dikker geworden; zij is in feite een eigen stelsel van economische wetenschap geworden, dat Goudriaan ons onder de ondertitel ,,inleiding tot de analytische economie" brengt. Elders ${ }^{2}$ ) had ik gelegenheid over de betekenis van dit boek voor het algemene publiek mijn zienswijze te geven. Daarbij heb ik het als een revolutionnair boek gekenmerkt, met de voor- en nadelen daarvan; terwijl ik meende te moeten stellen dat de voordelen niet gering zijn: de auteur is een scherpzinnig waarnemer en denker met een grote belezenheid en een boeiende betoogtrant, van wie men deswege geneigd is het een en ander op de koop toe te nemen. In dit artikel zal worden ingegaan op de wetenschappelijke zijde van zijn uiteenzettingen. Daarbij worde achtereenvolgens zijn bijdrage tot de verklaring der economische feiten en zijn bijdrage tot de leer der economische politiek besproken.

2. Wat de verklaring der feiten betreft, beweegt Goudriaans bijdrage zich vooral op het gebied der conjunctuurbewegingen, ofschoon zeker niet uitsluitend. Het hoofdelement van zijn theorie is dat van de onbepaaldheid van een aantal relaties, die in de gebruikelijke theorieën als bepaald of stochastisch worden behandeld en, als gevolg daarvan, de onbepaaldheid van een groot aantal economische grootheden. Met deze onbepaaldheid bedoelt de schijver aan te geven dat hun waarde (grootte) bin-

1) J. Goudriaan, Economie in Zestien Bladzijden. Inleiding tot de analytische economie. J. H. de Bussy. Amsterdam 1952. XXI, 249 blz.

2) Vrij Nederland, 23 Februari 1952.

Econ. 1952. 
nen wijde grenzen onzeker is, het ene ogenblik anders kan zijn dan het andere en dit op onvoorspelbare wijze en zonder dat daarbij een bepaalde frequentieverdeling kan worden voorspeld. Het sterkste is dat z.i. het geval met het prijsniveau der grondstoffen en met de bedrijvigheid in de kapitaalgoederenproductie; als gevolg daarvan treedt een zekere mate van onbepaaldheid in vrijwel alle economische grootheden op. Met deze onbepaaldheid bedoelt hij niet het met hetzelfde woord in de literatuur aangegeven verschijnsel van de onbepaaldheid van het statische evenwichtsprijsniveau, op een constante factor na, in sommige theoretische stelsels, maar een feitelijke onbepaaldheid bij kortetermijn bewegingen, als gevolg van de onbepaaldheid van het menselijk handelen. Deze onbepaaldheid kan tot grote afmetingen groeien, wanneer het optreden der kopers op een grondstoffenmarkt onderling gecorreleerd is, d.w.z. b.v. terughoudendheid van de een als een besmettelijke ziekte om zich heen grijpt en de anderen evenzeer tot terughoudendheid brengt. Een betrekkelijk kleine uitwendige oorzaak kan aldus, volgens Goudriaan, leiden tot een instorten van de grondstoffenprijzen en daarmede van de bereidheid tot het investeren, waardoor ook na enige tijd de gehele bedrijvigheid instort. Even onbetekenende factoren kunnen weer tot een omgekeerde beweging leiden. Aan te nemen, dat de conjunctuurbeweging een enigermate wetmatige cyclus zou vertonen, is zinloos; men kan altijd in een reeks toevallige cijfers op- en neergangen waarnemen; in het bijzonder wanneer men zo'n reeks eerst nog aan een aantal kunstbewerkingen onderwerpt, b.v. door voortschrijdende gemiddelden te bepalen. En hier sluit Goudriaan dan aan bij de resultaten van de bekende Russische mathematisch-statisticus Slutsky, die heeft aangetoond dat men op deze laatste wijze uit een rij toevallige getallen reeksen kan afleiden, die allerlei schijnbare cycli vertonen.

Op grond van deze overweging concludeert Goudriaan eveneens, dat veel van het tegenwoordige economisch-statistische of econometrische onderzoekingswerk ijdel en zonder zin is. Men zou zich in plaats van in het verklaren der economische schommelingen, beter kunnen verdiepen in de wijzen waarop men het verloop der economische grootheden stabieler, meer bepaald, zou kunnen maken. En daarop komen we dan terug bij de behandeling van het conjunctuurpolitieke vraagstuk. 
3. Hoe formuleert nu het moderne econometrische conjunctuuronderzoek zijn werkwijze en bevindingen? Men werkt daar dus niet met onbepaalde grootheden. Doch men doet toch wel iets, dat er niet zo verbazend ver van af staat. Men stelt nl. dat in een aantal relaties, zoals de economische theorie die heeft geformuleerd - vraag- en aanbodrelaties b.v. - twee soorten termen voorkomen. De vraag naar een bepaalde grondstof, zeggen wij b.v. katoen, hangt enerzijds af van een aantal bekende andere economische grootheden, zoals b.v. de prijs en de omvang van de industriële bedrijvigheid. De hiermee corresponderende termen in de vraagvergelijking worden ook wel de systematische termen genoemd. Daarnaast wordt de aanwezigheid van nietsystematische of storingstermen aangenomen. Deze vertegenwoordigen, naar de opvattingen van de meeste econometristen, alle niet nader te specificeren invloeden. Eensdeels zijn dat kleine invloeden, die men niet belangrijk acht, ofschoon men hun oorzaken misschien kan vaststellen. Anderdeels zijn het invloeden waarvan men de oorzaken niet kent. Er worden gewoonlijk ook toe gerekend de wisselingen in de oogsten, die weliswaar aan weersomstandigheden kunnen worden toegeschreven, maar toch niet op lange termijn van te voren bekend zijn en in die zin dus weer onbekend zijn. Doordat nu in een aantal relaties dergelijke storingstermen voorkomen, vertoont het geheel van de volkshuishouding inderdaad ook bewegingen die als toevallig kunnen worden betiteld. Daarnaast is er, als gevolg van de systematische termen, de neiging tot andere bewegingen. D.w.z. dat bij afwezigheid van storingstermen deze andere bewegingen zich zouden vertonen: de trendontwikkeling en, afhankelijk van een initiale storingsterm, een schommeling daaromheen of andere typen van bewegingen die we, naar het voorbeeld van de natuurkunde, de ,eigenbewegingen" zouden kunnen noemen. De werkelijke beweging is dan een aaneenschakeling van telkens weer gestoorde eigenbewegingen. Bekend is het beeld van de schommel, die op ongeregelde tijden een duw van uiteenlopende intensiteit ontvangt.

Het doel van de conjunctuurpolitiek zou, in deze voorstelling, zijn om de dempingsgraad van de eigenbewegingen zoveel mogelijk te vergroten. Daarmede kan geen eind gemaakt worden aan de toevallige storingen, zoals die door oogstbewegingen b.v. worden opgeleverd; maar wel aan de vergrotende, cumulatieve 
werking van de aan het economische stelsel inhaerente eigenbeweging. In plaats van cumulatief zou men deze dempend, ,smorend", kunnen maken.

Ook bij dit econometrisch conjunctuuronderzoek wordt dus niet meer het hoofdgewicht op de verklaring van, nog minder op de voorspelling van, de grillige onvoorspelbare feitelijke bewegingen gelegd - die niet interessant zijn - , maar op het doel om het stelsel stabieler te maken. Een doel dat met dat van professor Goudriaan identiek is.

4. In econometrische kringen wordt dus de stelling van Slutsky ook zonder meer aanvaard; men zou alleen kunnen zeggen, dat zij met een ander accent wordt uitgelegd. Niet zozeer is van belang dat een gewogen gemiddelde van toevallige bewegingen kan leiden tot quasi-schommelende bewegingen, maar eerder dat een bepaald gewogen gemiddelde van deze toevallige bewegingen tot quasischommelingen leidt, terwijl een op andere wijze gewogen gemiddelde dat in veel mindere mate doet. Het zijn juist de wegingscoëfficiënten in dat gemiddelde van Slutsky, die de structuureigenschappen van het economisch stelsel vertegenwoordigen; wat wij wensen is de structuur van de volkshuishouding zodanig te wijzigen, dat toevallige storingen in de kiem gesmoord worden en dus niet tot wijde schommelingen aanleiding geven. Zodanige structuurwijzigingen zijn dan, het zij ter verheldering even tussengevoegd, dus b.v. de compenserende uitgaven- en belastingpolitiek van de overheid of de grondstoffenvaluta of de aanbestedingen op afroep van Goudriaan.

$\mathrm{Bij}$ dit alles is het slechts van secundair belang, ofschoon feitelijk zeer belangwekkend, of nu die systematische eigenbewegingen golfbewegingen zijn dan wel eenzijdige van het evenwicht af gerichte bewegingen, die tot staan komen wanneer ze òf een plafond òf een bodem bereiken, om daar omgekeerd te worden, al of niet na een willekeurig tijdsinterval. Dit laatste type van eigenbewegingen is misschien - doch niet zeker - meer realistisch dan de golfbeweging, die uit zichzelf omkeert. ${ }^{3}$ ). Voor beide

3) Voor details over deze kwestie moge ik verwijzen naar mijn bijdrage in dit tijdschrift "Over verschillende soorten evenwichten en de conjunctuurbeweging", De Economist 92 (1943) blz. 129 e.v., waarvan de wiskundige verantwoording is verschenen als: J. Tinbergen, Ligevaegtstyper og Konjunkturbevægelse, Nordisk Tidskrift for Teknisk Økonomi, 1944, blz. 45 
geldt echter dat door vergroting van de dempingsgraad cumulatieve processen kunnen worden vermeden.

Het element nu van de onbepaalde grootheden van Goudriaan treedt in deze econometrische modellen op als de aanwezigheid, in bepaalde relaties, van de storingstermen. De grootheden in deze modellen zijn, naar de term die ook Goudriaan hanteert, stochastisch, d.w.z. ook binnen zekere grenzen onzeker. Het eigenlijke verschil tussen de de stochastische en de onbepaalde grootheden is, dat de eerste gedacht worden als aan een zekere waarschijnlijkheidsverdeling onderworpen, terwijl dit t.a.v. de onbepaalde grootheden niet zo wordt gesteld. Het onderscheid is, zo men wil, principieel, doch aan de andere kant theoretisch. Beide zijn in elk geval naar mijn mening indeterministisch. Het instrument van de waarschijnlijkheidsverdeling wordt toch immers ook slechts gehanteerd, wanneer men het eventueel aanwezige gedetermineerde verband buiten beschouwing wenst te laten. De strija tussen Goudriaan en zijn slachtoffers gaat dan om de vraag, hoe groot de onzekerheidsmarge is in bepaalde der relaties die het economisch gedrag beschrijven en of men de afwijkingen al of niet een waarschijnlijkheidsverdeling wil toekennen.

Hiermede zijn wij, naar mijn smaak, bij kwesties van uitwerking gekomen. Wij komen er dadelijk op terug. De hoofdzaak zou ik nog aldus willen samenvatten. Goudiaans verlangen om de onbepaaldheden uit het economisch stelsel te verwijderen en het verlangen der econometrische conjunctuuronderzoekers om de dempingsgraad der eigenbewegingen te vergroten, komen in de praktijk zeer dicht bijeen. Zij leiden ook tot voorstellen die in elkaars buurt liggen. Het is een kwestie van theoretische efficiëntie welke der benaderingswijzen men wil kiezen. En dan willen wij gaarne alle hulde brengen aan de architectuur van het model van Goudriaan, voor het eerst in de aflevering van December 1934 in dit tijdschrift gepubliceerd ${ }^{4}$ ) en in zijn huidige boek nader uitgewerkt. Doch aan de andere kant zijn toch de modellen der econometristen daarvan niet zo sterk afwijkend.

5. Komende tot de zoëven aangekondigde nadere uitwerking,

4) J. Goudriaan „Berekening van den omvang der werkloosheid als gevolg van prijsdaling in een gesloten economisch milieu", De Economist 83 (1934) blz. 849 . 
wil ik dan mijn instemming betuigen met Goudriaans poging om de markten aan te geven, die wel, en degene die niet voor gedetermineerde analyse in aanmerking komen. Wel komt het mij echter voor, dat hier verdere verfijning der onderscheidingen mogelijk is. Is het b.v. niet juist dat een vraag- en aanbodanalyse voor jaargemiddelden van de katoenmarkt wel mogelijk is, doch voor dag- of week- of maandgemiddelden niet? In zoverre zou zijn tableau op blz. 11 nog een zekere verfijning naar de tijdsduur waarop de analyse betrekking heeft, kunnen ondergaan. Wellicht is zijn bedoeling dat bij jaargemiddelden de vraag reeds identiek is met het verbruik, het aanbod met de productie en dat die in zijn tabel inderdaad als ,bepaald" zijn aangegeven. Voor het aanbod meen ik dat in elk geval te mogen weerspreken. De door de handel aangeboden hoeveelheid in een bepaald oogstjaar, zeg een jaar met een zeer grote oogst, is bepaald niet gelijk aan die oogst (plus de carry-over), doch hangt er wel systematisch mee samen ${ }^{5}$ ). Ook komt dan de vraag op, of niet de gemiddelde jaarprijs in zelkere zin als bepaald mag worden aangemerkt. In zoverre nl. als de conjunctuurstand, gemeten door het nationale inkomen of de productie van de kapitaalgoederenindustrie, als gegeven wordt aangenomen. Dit laatste mag men m.i., bij het beschrijven van een afzonderlijke markt als de katoenmarkt, inderdaad doen. Eerst als men het geheel van de volkshuishouding — of beter van de wereldhuishouding - tegelijk beschrijft, komt de onbepaaldheid weer tot uitdrukking. De wijze waarop, met andere woorden, de katoenmarkt meebeweegt met de algemene prijsbeweging is gedetermineerd; de algemene prijsbeweging echter is ongedetermineerd in Goudriaans zin. Dit is vermoedelijk ook wel Goudriaans mening, doch, indien het zo is, had het duidelijker kunnen worden gesteld.

$\mathrm{Bij}$ het schetsmatig aangegeven van de ,algebra der onbepaalde grootheden" op blz. 10 maakt de schrijver gebruik van de uitdrukking "simultane vergelijkingen"; wat hiermede bedoeld is, is mij niet duidelijk geworden. De tekst wekt de indruk dat hier bedoeld zijn relaties aan welke geen bepaalde causale richting kan worden toegekend. De naam zou dan minder geslaagd zijn.

5) J. Tinbergen, The notions of horizon and expectancy in dynamic economics, Econometrica 1 (1933), p. 247. 
6. Daar waar Goudriaan zijn bezwaren tegen de econometrische analyse van de korte schommelingen van grondstoffenmarkten het meest in detail uitwerkt, wijst hij op de mogelijkheid, dat de onbepaalde componenten in de vraag der afzonderlijke individuen sterk onderling gecorreleerd zijn, waardoor men niet langer kan stellen dat in de totale vraag de individuele afwijkingen elkaar grotendeels opheffen. Daardoor zou het werken met gedetermineerde relaties uitzichtloos zijn. Hij vestigt de indruk dat juist daardoor de statistische analyse van b.v. de baisse-speculatie zo weinig zin heeft. Het komt mij voor dat de meest karakteristieke elementen van deze baisse-speculatie echter ook op andere wijze gestyleerd kunnen worden. Het gaat daarbij niet om toevallige individuele afwijkingen van een systematische vraaglijn, doch om systematische afwijkingen, die van andere grootheden afhankelijk zijn als in de overgeleverde vraagfunctie worden opgenomen. In deze overgeleverde (statische) vraagfunctie houdt men rekening met de stand van de prijs, de inkomens, concurrerende prijzen enz. In de speculerende grondstoffenmarkt is de veranderingssnelheid van de prijs een belangrijke factor; wanneer de individuele kopers zich mede daardoor laten leiden, zal men deze factor dus in de vraagfunctie een -plaats geven en daarmede een goed deel van de onderling gecorreleerde individuele afwijkingen van de ,toevallige" naar de systematische term kunnen overbrengen. Daardoor zou de dan nog overblijvende toevallige afwijking weer wel ongecorreleerd zijn.

Zelfs indien men zou willen bestrijden dat het veranderingssnelheid van de prijs is, die hier opereert, en een directe invloed van de decisies van de ene koper op die van de andere willen erkennen, is er nog zeer goed een gedetermineerde stylering van het marktmechanisme mogelijk. Laat de vraag van individu $i$ door $x_{1}$ weergegeven worden en laat de verandering $\lrcorner x_{1}$ behalve door een systematische invloed $\xi_{i} s$ mede bepaald worden door de $\Delta x_{1}$ van andere kopers. Dan zou men, micro-economisch, kunnen stellen:

$$
\Delta x_{1}=\Sigma_{1} \xi_{4} d x_{1}+\xi_{1} s
$$

Uit de $n$ vergelijkingen voor het gedrag der $n$ kopers zouden de $\Delta x_{1}$ dan toch weer kunnen worden opgelost en in de $s$ worden uitgedrukt. De mogelijkheden van een deterministische aanpak zijn hier dus nog niet uitgeput. 
Zou men hierop tegenwerpen dat het weinig nut heeft dit te doen, dan ben ik geneigd dit te aanvaarden. Dat is dan echter een andere kwestie dan principrèle ongeoorloofdheid. Evenzeer als Goudriaan geen behoefte gevoelt aan een deterministische oplossing, kan een ander daaraan wel behoefte hebben.

7. In deze bespreking van de finesses passen nog twee kritische opmerkingen van geheel ander karakter. De ene is dat het opvalt dat Goudriaan op blz. 8 of in de toelichting daarop de naam van Dr Chait niet noemt, die de daar geformuleerde gedachten in veel meer uitgewerkte vorm heeft gepubliceerd in zijn „Les fluctuations économiques et l'interdépendance des marchés", waarop hij in 1938 aan de Universiteit van Parijs is gepromoveerd; Professor Divisia stelt dit werk op één lijn met het werk van Walras ${ }^{\circ}$ ).

De andere opmerking betreft het uiterlijk van het boek. In algemene zin past daarvoor slechts lof; doch de afwezigheid van een register en van een bladzijden-aanduiding in de inhoudsopgave, alsmede de onjuiste tekens die in de plaats van $A$ en $\partial$ zijn gebruikt, moeten mij van het hart. Wellicht kan een volgende oplage deze „manque d'élégance” vermijden.

8. Terugkerende tot belangrijke zaken - waartoe men mijn laatste opmerking niet zal rekenen - moge ik nu over de economisch-politieke zijde van het boek nog een enkele opmerking maken. Hierbij kenmerkt zich Goudriaans program vooral door zijn pleidooi voor wat de Amerikanen thans noemen ,built-in stabilisers" als instrumenten van conjunctuurpolitiek. De hoofdelementen van zijn programma zijn toch immers de grondstoffenvaluta en het stelsel van de ,aanbestedingen op afroep", waarvan het automatisme vooral door Goudriaan als voordeel naar voren wordt gebracht. Zijn desbetreffende argumentatie is de moeite van het lezen waard in deze tijd van voorliefde voor gedetailleerde ,ordening”. Zij verdient meer aandacht dan men in het algemeen er aan gegeven heeft. De korte discussie die zijn voorstellen indertijd hebben uitgelokt, was maar weinig overtuigend wat de tegenargumenten aangaat. Een ernstige weging van voor- en tegenargumenten door een groep deskundigen op theoretisch en practisch terrein en op internationaal niveau komt mij nog altijd noodzakelijk voor.

6) F. Divisia, L'apport des ingénieurs français aux sciences économiques (Exposés d'économique I), Paris 1950, blz. 83. 
Van de zuiver-economische kant verdienen nog twee aspecten van de voorstellen bijzondere aandacht. Goudriaan is een overtuigd voorstander van de gedachte, dat de conjunctuurstabilisatie moet plaats vinden op het hoogste niveau van bedrijvigheid, niet op een ,gemiddeld" niveau. De opvatting dat er een zinvol gemiddelde van activiteit bestaan, waarboven men niet moet trachten te blijven omdat dan een onvermijdelijke terugslag zal komen, wijst hij, m.i. terecht, als „mystiek" af. Hij gaat daarbij zelfs zover, dat hij een werkloosheid van niet meer dan $2 \%$ een juist criterium acht. De depressies zijn, althans internationaal bezien, nodeloze afwijkingen naar beneden daarvan. Of men in plaats van $2 \%$ niet beter $3 \%$ kan nemen, moge thans in het midden worden gelaten. Op de internationale complicaties gaat de schrijver niet of nauwelijks in. Dat is ook niet de opzet van het boek. In de practijk van een klein land spelen deze echter natuurlijk wel een grote rol.

De gedachte voorts dat mèn er met weinig, krachtig werkende, automatische regulatoren kan komen, is aantrekkelijk, doch niet geheel aanvaardbaar voor wie te maken hebben met betrekkelijk ernstige verstoringen van het economisch evenwicht, zoals de regeringen-in West-Europa na de Tweede Wereldoorlog, en waarschijnlijk evenmin wanneer men de slachtoffers van economische dislocaties op minder hardhandige wijze de juiste weg wil wijzen, dan b.v. is geschied met onze landbouwers in de periode van 1875-1900. Want zulke hardhandigheden zal men tegenover structurele werkloosheid toch vermoedelijk moeten toepassen, wanneer men slechts een juiste algemene conjunctuurpolitiek wil voeren en de verdere aanpassingen alle aan de individuen wil overlaten. Men kan zich daarom voorstellen dat enige meerdere instrumenten van economische politiek door de meeste tegenwoordige regeringen worden verlangd. Maar ik ben geneigd, cvenals Goudriaan, het gebruik van te veel en te veel incidentele en individuele instrumenten als minder efficiënt te beschouwen. Hier komen wij op het terrein van de systematische bestudering van de efficiëntie van alternatieve vormen van economische politiek. Dit gebied begint meer en meer de aandacht te vragen ook van meer algemene onderzoekingen. Het is nog nauwelijks in een algemeen-aanvaarde vorm in wetenschap en onderwijs geïncorporeerd. Met de ervaring over hele en halve planning in uiteenlopende vormen wordt een zekere bezinning op dit terrein 
nu ook mogelijk. Enkele pogingen tot samenvattende beschouwingen zijn nu ook gedaan '), zij het meestal nog in sterk polemische vorm. Pogingen tot meer geëquilibreerde afweging van voor- en nadelen zullen nog moeten worden toegevoegd. Goudriaan heeft daarbij bouwstenen van veel belang aangebracht. Hij heeft daarbij diep gegraven: aan de ene kant is hij tot de grondslagen van het economisch denken teruggegaan, terwijl hij aan de andere kant tal van concrete practische aspecten in zijn programma heeft betrokken. Bij dit omvangrijke werk heeft hij met zijn eigen tijd moeten woekeren. en streng geselecteerd wat hem belangrijk en wat niet belangrijk leek. Men zal niet kunnen ontkennnen dat hij daarbij visie heeft ontwikkeld en ,nieuwe combinaties" aangegeven. Dat hij daarbij wel eens klappen heeft uitgedeeld, die niet geheel verdiend zijn of ook een enkele slag in de lucht, is geen wonder.

7) Zie bv. J. Jewkes, Ordeal by Planning, London 1948; W. Keilhau, Principles of Private and Public Planning, Londen 1951. 